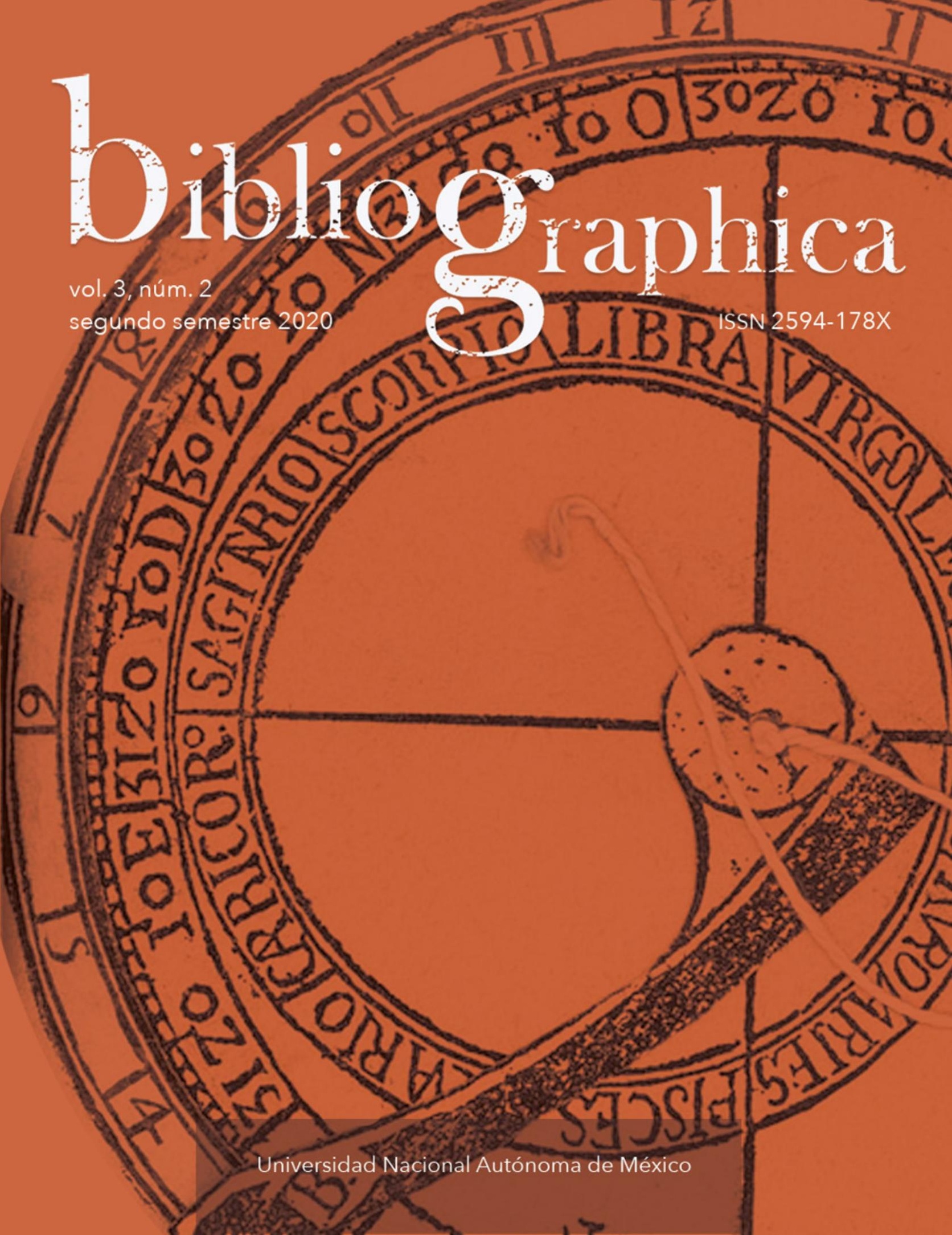




\title{
Libros y bibliotecas en la vida sociopolítica de Ignacio Ramírez, el Nigromante
}

\author{
Books and Libraries in the Sociopolitical Life \\ of Ignacio Ramírez, the Necromancer
}

\section{Felipe Meneses Tello}

fmeneses@unam.mx

\section{María de los Ángeles Avelar Mayer}

avelarmayerma@gmail.com

Universidad Nacional Autónoma de México

Facultad de Filosofía y Letras

Recepción: 18.05.2020 / Aceptación: 06.07.2020

DOI: https://doi.org/10.22201/iib.2594178xe.2020.2.84 
Resumen

Palabras clave

Abstract

Keywords
A más de 200 años de su natalicio, se estudian y analizan algunos perfiles de la vida de Ignacio Ramírez, personaje famoso en la historia política del siglo XIX. Escritor, poeta, periodista, abogado, profesor, político e ideólogo liberal mexicano, muestra el modelo del intelectual que habría de surgir a la vida pública, teniendo como base un recio marco cultural de libros y bibliotecas, de intensa dedicación a la lectura crítica. En este sentido, se infiere que las colecciones bibliográficas que tuvo a su alcance le permitieron figurar notablemente en las diferentes etapas de su quehacer intelectual, esto es como lector y autor, escritor y orador, maestro y periodista, vate y jurisconsulto, funcionario y reformador. Asimismo, se explora la influencia de su trabajo político en la creación de importantes instituciones bibliotecarias durante el movimiento de la Reforma y el periodo de la República Restaurada.

Ignacio Ramírez, el Nigromante; libros; bibliotecas; siglo XIX; política; historia.

More than 200 years after his birth, various facets of Ignacio Ramírez' life are studied and analyzed. Ramírez was a well-known character in $19^{\text {th }}$ century's political history. As a Mexican writer, poet, journalist, lawyer, teacher, politician and liberal ideologue, he portrays the model of the intellectual that sprang to public life based on a robust cultural framework of books and libraries and a strong dedication to critical reading. In this context, it is inferred that the book collections in the libraries at his disposal had a notable effect on the various stages of his academic endeavors. In other words, they shaped his work as scholar, reader and author, writer and speaker, teacher and journalist, foreseer and legal adviser, as a civil servant and reformer. Additionally, the influence of his political work in the creation of important libraries during the Reform movement and the Restored Republic period is explored.

Ignacio Ramírez, the Necromancer; books; libraries; $19^{\text {th }}$ century; politics; history. 
Entre los monumentos del porvenir bien merece señalarse, como de los primeros, cualquiera biblioteca.

El Nigromante, 1874.

\section{Introducción}

El 22 de junio de 2018 se cumplieron 200 años del nacimiento de Ignacio Ramírez, uno de los principales personajes del ala política liberal del siglo XIX, cuyas aportaciones son consideradas de gran relevancia en las diferentes esferas de la sociedad y el Estado. Figura prominente del Estado laico mexicano, Juan Ignacio Paulino Ramírez Calzada (1818-1879), conocido también bajo el seudónimo periodístico del Nigromante, es un personaje de la historia del México decimonónico que brilla en el marco de una pléyade de políticos cultos que lograron consolidar la Independencia y gestar una nueva nación, bajo la directriz de los valores democráticos y republicanos.

Se le reconoce históricamente como uno de "aquellos gigantes de la reforma", uno de los "titanes que supieron combatir una invasión extranjera y sepultar un imperio", 1 además de que se propuso promover "un cambio radical de las estructuras políticas, sociales, económicas y culturales en vigencia".2 En el contexto del intenso movimiento de la Reforma, brilló por su agudo pensamiento y su penetrante y ágil pluma. Como voraz lector, mostró la relevancia de las bibliotecas en sus años de formación académica; como natural polígrafo, reflejó su convicción por el poder de la letra impresa. Se forjó en la fragua del liberalismo rojo y perteneció a la hornada de la ilustración autodidacta que enfrentó la política oscurantista que el México independiente había heredado de Nueva España.

Sus principales armas intelectuales para colaborar en la restauración del gobierno republicano fueron los impresos, la pluma, tintero y papel. Su obra escrita, reunida en ocho volúmenes, es clara evidencia de que perteneció al grupo de empeñados pensadores que lucharon ideológicamente por el florecimiento de una nueva nación mexicana. En el marco de la historia de México el Nigromante es considerado polemista, político, orador, periodista, parlamentario, filólogo, abogado, maestro, naturista, geógrafo, historiador, escritor y juez, entre otras vocaciones y actividades.

\footnotetext{
1 Jorge Fernández Ruiz, Juárez y sus contemporáneos (México: UNAM, 1986), 368.

${ }^{2}$ David Maciel, Ignacio Ramírez: ideólogo del liberalismo social en México (México: Secretaría de Cultura / INEHRM, 2018), 25.
} 
Concordamos con el punto de vista que asevera: "Es sorprendente que un intelectual de su talla no haya recibido mayor atención en la literatura académica, ya sea sobre aspectos específicos de su extenso legado o a través de una monografía que analice el conjunto de su legado". ${ }^{3}$ Lo mismo ha sucedido en el campo de las especialidades del libro y las bibliotecas (bibliotecología, biblioteconomía, bibliología, bibliografía); advertimos que en el marco de la creación definitiva de la Biblioteca Nacional de México, la participación de Ignacio Ramírez ha sido ignorada u omitida.

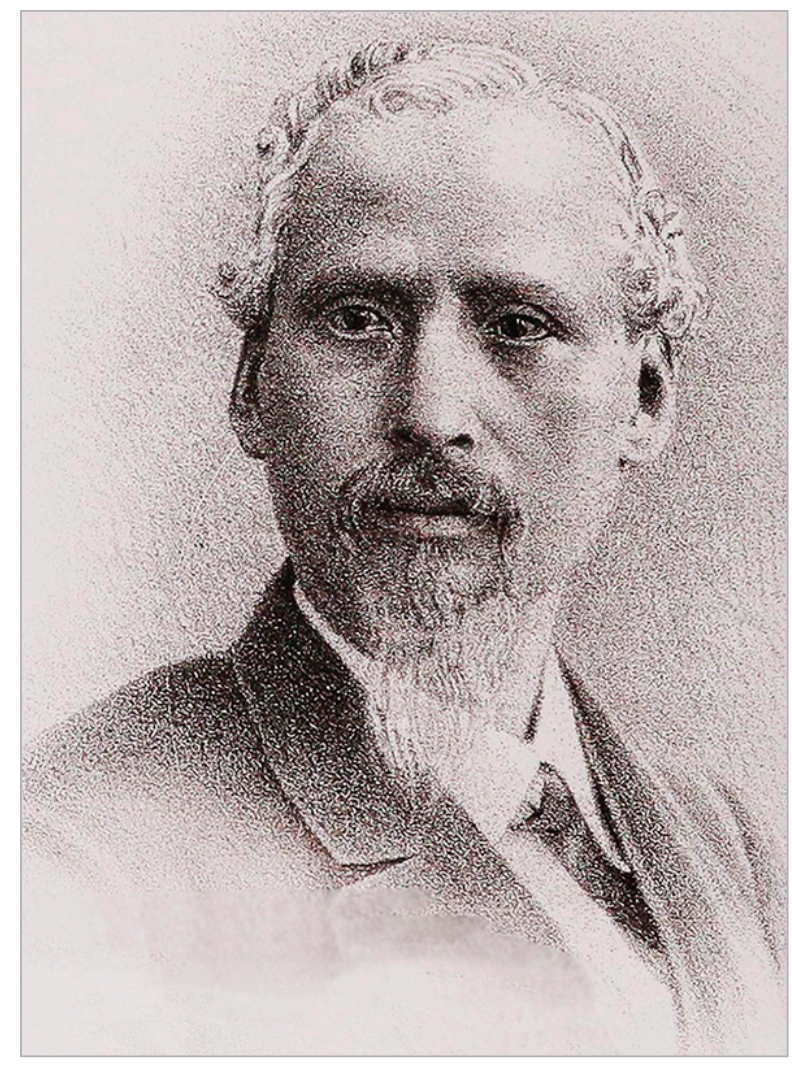

Imagen tomada de Obras de Ignacio Ramírez (México: Secretaría de Fomento, 1889).

\footnotetext{
${ }^{3}$ Ibid., 16.
} 


\section{Esbozo biográfico}

Nació en San Miguel El Grande (hoy San Miguel de Allende), el 22 de junio de 1818. Sus padres -José Anselmo Lino Ramírez Galván, jurisconsulto e insurgente, y Ana María Guadalupe Sinforosa Calzada, descendiente de caciques indígenas-, interesados en brindarle una buena educación, en 1835 lo enviaron a Ciudad de México para que ingresara al Colegio de San Gregorio, en ese entonces dirigido por Juan Rodríguez Puebla (1798-1848), rector que difundió las ideas de igualdad, libertad y fraternidad, valores que marcarían el sentir democrático de muchos de los liberales ilustres que formaron parte del movimiento de Reforma. ${ }^{4}$ De 1837 a 1841 estudió jurisprudencia en el Colegio de Abogados, perteneciente a la Real y Pontificia Universidad de México.

En el plano del periodismo, fundó en 1845 -con Guillermo Prieto y Vicente Segura Argüelles, bajo la administración de Manuel Payno- el diario Don Simplicio, en el cual usó por vez primera el seudónimo el Nigromante. En 1848 publicó A los indios en Temis y Deucalión, por lo que fue detenido bajo el cargo de haber cometido delitos de imprenta, acusación de la cual quedó absuelto gracias a sus artículos publicados en El Demócrata. En 1857 publicó El Porvenir y El Clamor Progresista (ambos de breve duración) para mostrar su inconformidad con el gobierno de Ignacio Comonfort, hecho que lo llevó a otra estancia en prisión. Colaboró en diversos periódicos como El Precursor y La Sombra de Robespierre; en 1863 fundó el periódico antiimperialista La Chinaca; a finales de 1864 escribió en La Opinión y en Estrella de Occidente, rotativos del estado de Sonora.

En 1865 fundó La Insurrección, donde sostuvo una enconada polémica con el panhispanista Emilio Castelar, polígrafo español que resultó derrotado. En 1867 fundó El Correo de México, en el que se pronunció contra la permanencia de Benito Juárez (1858-1872) al frente del poder Ejecutivo, para apoyar posteriormente en El Mensajero (1871) a Porfirio Díaz. Sin dar descanso a su pluma, continuó escribiendo (de 1872 a 1875) en diversos periódicos de corte liberal como El Federalista, El Monitor Republicano y El Siglo Diez y Nueve.

Ramírez elaboró, en 1877, las ilustraciones para el libro Anatomía humana y cirugía de Luis Jecker, director de la Escuela de Cirugía Mexicana. ${ }^{5}$ De igual

\footnotetext{
${ }^{4}$ Lilian Álvarez Arellano, "El Colegio de San Gregorio: modelo de educación para los indios mexicanos", Chicomoztoc 8 (2013): 101-117, acceso el 12 de agosto de 2020, http://www.descolonizacion.unam.mx/pdf/Ch8_9_gregorio.pdf.

${ }^{5}$ Emilio Arellano, Ignacio Ramírez: El Nigromante: Memorias prohibidas (México: UAEM / Editorial Planeta Mexicana, 2016), 62.
} 
forma, su interés y respeto por las culturas indígenas quedó asentado en sus traducciones de jeroglíficos mayas (1850), del Diccionario del idioma maya, publicado por J. Williams, así como del Diccionario español-náhuatl; también asimiló conocimientos sobre los jeroglíficos náhuatl, quiché y otomí. Por otro lado, destacan sus contribuciones en algunos libros colectivos: Apuntes para la historia de la guerra entre México y los Estados Unidos (1848), en colaboración con 15 personalidades, como Guillermo Prieto y Manuel Payno, y Los Mexicanos pintados por sí mismos (1854), donde compartió autoría con Hilarión Frías y Soto, José María Rivera, Pantaleón Tovar y Niceto de Zamacois. En 1870 Ramírez fue nombrado presidente de la Sociedad Mexicana de Geografía y Estadística, fundada en 1833.

Tuvo también una importante carrera política y un fructífero desarrollo dentro de la función pública. En 1846 Francisco de Olaguíbel, gobernador del Estado de México, lo designó secretario de Guerra y Hacienda, cargo en el cual ordenó la reapertura del Instituto Científico y Literario de Toluca y promovió la Ley de los alumnos de gracia o municipalidad, que instaba a que los municipios mandasen pensionados a alumnos indígenas de escasos recursos; ${ }^{6}$ gracias a ello mentes brillantes, como la de Ignacio Manuel Altamirano, pudieron acceder a un mejor nivel educativo.

En términos generales, sobre el Nigromante se afirma los siguiente: "Su actividad política abarcó los conflictos ideológicos y militares más dramáticos del siglo XIX: la Revolución de Ayutla, 1854; el Congreso Constituyente de 18561857; la Reforma, 1857-1860; Ia Intervención francesa, 1863-1867; la República Restaurada, 1867-1876; la revuelta de Tuxtepec y el advenimiento del Porfiriato".

Tras el triunfo de la Revolución de Tuxtepec, Porfirio Díaz lo nombró ministro de Justicia e Instrucción Pública, lo cual le permitió reorganizar la educación elemental, la Escuela Nacional Preparatoria e implementar la versión actualizada del plan de estudios que incluía biología, matemáticas e inglés. En 1877 renunció a ese puesto para reincorporarse como ministro de la Suprema Corte de Justicia, cargo que ejerció hasta su muerte.

${ }^{6}$ Graciela Isabel Badía Muñoz, "Breve reseña histórica del Instituto Literario de la Ciudad de Toluca hasta la conformación de la Universidad Autónoma del Estado de México", La Colmena: Revista de la Universidad Autónoma del Estado de México, núm. 50 (2006): 25. 7 Laura Ibarra García, "Las ideas de Ignacio Ramírez, El Nigromante: su significado en la historia del pensamiento mexicano", Iztapalapa. Revista de Ciencias Sociales y Humanidades 72, núm. 33 (2012): 154-155. 


\section{El contexto bibliotecario que vivió Ramírez}

Este tema fue determinante, tanto para lograr un alto nivel de conocimientos como para aquilatar la relevancia de las bibliotecas en el entramado de los servicios públicos que requería la nueva república. La biblioteca que perteneció al Colegio de San Gregorio era una de las cinco principales de la Ciudad de México, las otras sobresalientes eran las de la Pontificia Universidad, la del Colegio de San Ildefonso, la del Colegio de San Juan de Letrán y la de la Catedral, mejor conocida como la Biblioteca Turriana. ${ }^{8}$

En dos obras decimonónicas se constatan las cifras aproximadas de los acervos de esas preponderantes bibliotecas. El libro México pintoresco, artístico y monumental asevera que: "Las grandes bibliotecas de la capital eran cinco: la de la catedral con casi trece mil volúmenes impresos y manuscritos; la de la Universidad con nueve mil y San Gregorio poseía cuatro mil; San Juan de Letrán de once a doce mil y San Ildefonso tenía ocho mil trescientos".9 Sin embargo, cabe aclarar que esos datos Manuel Rivera Cambas debió tomarlos de la Guía de forasteros, y repertorio de conocimientos útiles, ${ }^{10}$ publicada 30 años antes y que consigna las mismas cifras. No sólo se consideró la cantidad de volúmenes, sino que también se aquilató la calidad de esos grandes acervos, factores que serían tanto elogiados como criticados por la intelectualidad del siglo XIX.

La mejora de las colecciones del centro bibliotecario del Colegio de San Gregorio se debe a su autoridad rectora, pues:

Rodríguez promovió el incremento del acervo de la biblioteca, el cual constaba principalmente de textos religiosos escritos en distintas lenguas. De tal modo, a partir de 1829 el rector se dio a la tarea de inventariar e incrementar el acervo en el área científica y en la de las humanidades, entre ellas la de documentos americanos. Todo ello con donaciones de personajes como Agustín Torres Torrija, Pablo de la Llave y Mariano Otero, entre otros.

\footnotetext{
${ }^{8}$ Ignacio Osorio Romero y Boris Berenzon Gorn, "Biblioteca Nacional de México", en Historia de las bibliotecas nacionales de Iberoamérica, coord. de José G. Moreno de Alba y Elsa Margarita Ramírez Leyva (México: UNAM, Coordinación de Humanidades, 1995), 328-329. 9 Manuel Rivera Cambas, "Biblioteca Nacional", en México pintoresco, artístico y monumental, t. 2. (México: Imprenta de la Reforma, 1882), 220.

10 Juan Nepomuceno Almonte, Guía de forasteros, y repertorio de conocimientos útiles (México: Imprenta de I. Cumplido, 1852), 485.
} 
Después de la muerte de Rodríguez Puebla, los rectores que le sucedieron continuaron incrementando la colección de la biblioteca hasta convertirla en espacio público en $1850 .{ }^{11}$

Hay que valorar en su justa dimensión el aumento de las colecciones de esta biblioteca. Si tenemos en cuenta la crisis económica por la que atravesaba la República, podemos intuir que su desarrollo se llevó a cabo mediante la adquisición de acervos particulares. Si consideramos los antecedentes intelectuales, por ejemplo, de Pablo de la Llave (1773-1833), entonces gracias a este político y naturalista mexicano esta biblioteca pudo haber recibido títulos sobre asuntos propios de las ciencias naturales (biología, botánica, zoología, ornitología); por parte de Mariano Otero (1817-1850), como jurista y político mexicano, es posible que los fondos bibliográficos se hayan incrementado en diversas ramas de derecho (natural, político y civil), así como en temas relativos a economía, política e historia, entre otras disciplinas afines.

Otro antecedente importante del contexto bibliotecario que vivió Ignacio Ramírez es la apertura de las bibliotecas al público. Fuentes consultadas aseveran que en 1845 Rodríguez Puebla, dado su interés por la instrucción pública, logró que "se hiciera la apertura solemne de la biblioteca para el público"12 con 3383 libros. ${ }^{13}$

Por otra parte, la Biblioteca de la Catedral Metropolitana, legado cultural novohispano, tuvo -por disposición de sus fundadores Luis Antonio Torres Quintero, Cayetano Antonio de Torres Tuñón y Luis Antonio de Torres Tuñón- un carácter de uso público y gratuito, y en su época fue considerada la mejor y la más concurrida. Nuestro personaje nutrió su intelecto durante un largo periodo en esos centros bibliotecarios, en virtud de que:

Durante ocho años Ignacio Ramírez es el voluntario e inteligente huésped de las bibliotecas gregoriana y catedralicia; incansable devorador de libros. Con

\footnotetext{
${ }^{11}$ María Eugenia Xilonetl Flores Rodríguez, "Juan de Dios Rodríguez Puebla: en defensa de la instrucción para los indios", en El Estado laico y los derechos humanos: 1810-2010, t. 1, coord. de Margarita Moreno Bonett y Rosa María Álvarez de Lara (México: UNAM, IIJ, FFyL, 2012), 416-417.

12 Lucas Alamán, José María Andrade et al., Diccionario universal de historia y geografía, t. 1 (México: Tipografía de Rafael / Librería Andrade, 1853), 593.

${ }^{13}$ Ignacio Osorio Romero, Historia de las bibliotecas novohispanas (México: SEP, 1986), 204.
} 
inimaginable espíritu de autodidacto; ávido de investigar el porqué de las cosas, sus causas y sus efectos, todo lo estudia y acomete con singular entusiasmo. Y todo le interesa: Matemáticas, Química, Biología, Historia, Astronomía, Geografía, Fisiología y hasta Teología escolástica. [...] Apasionado de las Ciencias y las Artes, amplía siempre sus estudios y conocimientos científicos en gabinetes y laboratorios, completando las teóricas nociones adquiridas. ${ }^{14}$

Si consideramos varios factores, como la naturaleza temática de una parte de las colecciones, la disposición restringida de los recursos bibliográficos y el limitado horario de servicio al público, entre otros, esos espacios de lectura fueron más bien protopúblicos o semipúblicos, pues el desarrollo de las verdaderas bibliotecas públicas inició su lenta andadura a partir de 1850. A pesar de esto, el hecho de abrir esos centros bibliotecarios al público, entre el ocaso de la Colonia y los albores de la Independencia, fue un importante acontecimiento para quienes tenían el hábito de estudiar más allá de lo que demandaban determinados planes académicos de estudio, como Ramírez.

El adelanto y pujanza de ese servicio colegial de biblioteca ocurrieron en 1829-1848, durante la rectoría de Rodríguez Puebla. Ramírez fue testigo de un proyecto de servicio bibliotecario que ayudó a formar a un grupo sobresaliente de lectores durante los años de la Intervención francesa (1838-1839; 1862-1867), la Invasión estadounidense (1846-1848) y la Guerra de Reforma (1858-1861), que fue parte del movimiento de Reforma (1833-1861). El Colegio de San Gregorio, con su biblioteca, fue un vivero donde se cultivó uno de los congresistas de 1857, un liberal que entre sus proyectos políticos de reforma incluyó las bibliotecas religiosas para ponerlas, junto con otras instituciones, en manos de la administración del estado republicano.

Para percibir desde otras aristas el contexto bibliotecario en el cual Ramírez se desenvolvió, mencionaremos algunas apreciaciones de las otras tres principales bibliotecas capitalinas, que sin duda conoció. De la Biblioteca de la Real y Pontificia Universidad de México se afirma que "no nació con la Universidad, sino casi dos siglos después", a pesar de lo cual fue "una de las más valiosas de la Nueva España". ${ }^{15}$ Ese servicio bibliotecario data del siglo XVIII y en tiempos

\footnotetext{
${ }^{14}$ Alfonso Sierra Partida, Ignacio Ramírez: espada y pluma (México: Memphis, 1960), 18-19.

${ }^{15}$ Alberto María Carreño, La Real y Pontificia Universidad de México 1536-1865 (México: UNAM, 1961), 291.
} 
de Ramírez no era tan antigua, sin embargo se caracterizó "por la hermosura de su fábrica, el número de volúmenes, la exacta clasificación de las materias, y su buena organización para el servicio público". Poseía un selecto acervo que ascendía, a mediados del siglo XIX, a 9 mil volúmenes donados y comprados, entre los que destacaban los libros sobre teología, medicina y política.

La Biblioteca del Colegio de San Ildefonso, de origen novohispano y con un historial de serios contratiempos en cuanto a su conservación, era considerada "un monumento glorioso de la llustración" y, si no hubiese sido por los difíciles momentos que pasó, antes y después de la Independencia de México, estaría entre una de las primeras bibliotecas de la República. Por lo que respecta a la Biblioteca del Colegio de San Juan de Letrán, se afirmaba a mediados del siglo XIX: "es muy abundante por el número de obras que contiene", adquiridas por compra y donación, si bien muchas estaban truncas. En cuanto a la organización de la colección, fue "dividida en dos partes, que se encuentran en departamentos separados. La una contiene obras propias para el estudio de los alumnos y se les franquea enteramente para que usen de ellas; la otra, contiene todas las demás obras, y se franquea con anuencia del rector". ${ }^{16}$ Recordemos que las tertulias de la Academia de Letrán - de la cual fue distinguido miembro Ignacio Ramírez- tenían lugar en ese espacio bibliográfico.

La esencia de la vida y obra intelectual de Ramírez gira en torno al tiempo que dedicó a hacer uso de las colecciones de esas connotadas bibliotecas que había en la ciudad capital. Dicho contexto bibliotecario pudo favorecerlo para salir avante en sus proyectos de estudiante y estudioso, como escritor y político. Un factor esencial para aquilatar la importancia de estas bibliotecas fue la cantidad de libros que constituían sus fondos. Juan Nepomuceno Almonte (1803-1869), hijo del sacerdote insurgente y revolucionario José María Morelos y Pavón y partidario del emperador Maximiliano de Habsburgo, hizo alusión al número de volúmenes que contenían, así como a otras posibilidades de lectura pública, pero no gratuita, que había en la Ciudad de México:

De las primeras [bibliotecas públicas], hay en la capital tres, que son: la de la Catedral, que consta de más de trece mil volúmenes impresos y manuscritos; la de la Universidad, que tiene sobre nueve mil, y la de San Gregorio, con más de cuatro mil. Además de estas, hay otras librerías y gabinetes de lectura,

\footnotetext{
${ }^{16}$ Alamán et al., Diccionario universal, 590, 593, 596.
} 
pertenecientes a particulares, cuyas obras puede leer el público pagando el precio de suscripción establecidos en ellos. ${ }^{17}$

Según Almonte, los centros bibliotecarios de San Juan de Letrán y de San Ildefonso eran "bibliotecas para el uso de los colegios", el primero con entre 11 y 12 mil volúmenes, y el segundo con casi 8 400. En esta perspectiva institucional, afirmaba que había pocas bibliotecas públicas, en contraste con las particulares, que a mediados del siglo XIX eran muy numerosas. Cabe aclarar que el concepto de biblioteca pública de aquel tiempo no se ajusta al que comenzó a evolucionar, con base en la teoría, historia y práctica de la bibliotecología, a lo largo del siglo XX.

Las opiniones contrastaban en cuanto a la valoración pública de las principales bibliotecas existentes. Esta justipreciación giraba principalmente en torno al tamaño de las colecciones, pues se ponderaba la cantidad de los libros antiguos respecto a los modernos, al igual que la distancia que debían recorrer los interesados para llegar a esas instituciones de lectura. Con estos argumentos se expuso, en los albores de la segunda mitad del siglo XIX, la necesidad y exigencia de crear la Biblioteca Nacional de México. En el periódico El Universal apareció la siguiente crítica:

Existen en México tres bibliotecas públicas, que sirven de muy poco para los objetos a que están destinadas: la de la santa iglesia Catedral, bien surtida de muchas obras antiguas, pero que carece de obras modernas; la de la Universidad, que sin contar con igual ventaja, tiene el mismo inconveniente; y la del Colegio de San Gregorio que, aunque fuera muy buena, no serviría de nada porque están en San Jacinto, a una legua de la capital. ${ }^{18}$

Para más detalles sobre el legado cultural novohispano predominante a partir de 1821 en materia de bibliotecas, se sugiere leer antecedentes de otros centros bibliotecarios que quizá conoció Ramírez siendo aún joven, como la biblioteca del Colegio de San Pablo, la de Santa María de Todos los Santos, la de la Real Academia de San Carlos y la del Real Colegio Seminario de Minería, espacios bibliográficos que existieron en la capital durante el periodo ilustrado,

\footnotetext{
${ }_{17}$ Almonte, Guía de forasteros, 485.

18 "Creación de una biblioteca nacional", El Universal. Periódico Político y Literario, 4 de agosto de 1854: 1.
} 
entre 1767-1821, ${ }^{19}$ pero que heredó la intelectualidad liberal del México independiente, de la cual Ignacio Ramírez formó parte. Es probable que también haya utilizado la Biblioteca del Instituto Científico y Literario de Toluca, plantel donde impartió clases.

\section{El joven escolar entre libros y bibliotecas}

En Tendencias educativas oficiales en México 1821-1911, los autores sintetizan la formación de Ignacio Ramírez: "A los 16 años llega a la capital y cursa sus estudios bajo la dirección del liberal Juan Rodríguez Puebla en el Colegio de San Gregorio. Estudiante distinguido en los cursos de artes, pasa luego a jurisprudencia donde concluye la carrera de abogado". ${ }^{20}$ Cuando llegó a ese afamado colegio ya había adquirido cierto hábito de la lectura a través del castigo paterno, impuesto por rechazar ir a la misa dominical con sus progenitores. El "anhelado castigo" consistía en quedarse encerrado en el despacho de su padre,

tiempo que aprovechaba el niño para leer los libros prohibidos de Voltaire, hojear las litografías de la conquista de Tenochtitlán y un libro censurado por la iglesia intitulado El judío errante, escrito por un religioso esenio y traducido del latín en el siglo IV. Cuando su querido padre se enteró de que su hijo leía esos libros, de inmediato negoció con el niño que si iba a misa le explicaría los temas y comentarían juntos esos tesoros del saber. Ramírez aceptó y de verdad disfrutaban juntos la tertulia literaria con su progenitor. ${ }^{21}$

Cuando su padre fue vicegobernador de Querétaro entre 1833 y 1834, Ignacio utilizó algunos acervos clericales, en concreto los pertenecientes a la biblioteca conventual de San Francisco. Al respecto, Guillermo Prieto anota que en ese monasterio Ramírez "conoció íntimamente la vida de los frailes, en todos los pormenores de sus especulaciones místicas, y al mismo tiempo, encerrado en las bibliotecas, adquirió desde entonces asombrosa erudición".22 Aunque

\footnotetext{
${ }^{19}$ Osorio, Historia de las bibliotecas, 119-255.

${ }^{20}$ Ernesto Meneses Morales, Liliana Bedoy Lazo et al., Tendencias educativas oficiales en México 1821-1911: la problemática de la educación mexicana en el siglo XIX y principios del siglo XX, 2a. ed. (México: Universidad Iberoamericana, Centro de Estudios Educativos, 1998), 176.

${ }^{21}$ Arellano, Ignacio Ramírez, 27.

22 Guillermo Prieto, Memorias de mis tiempos, 3a. ed. (México: Editorial Porrúa, 2004), 116.
} 
esas colecciones debieron ser predominantemente teológicas (biblias, santorales, misales, etcétera), también había libros de filosofía, biología y literatura, entre otras disciplinas.

La frase "encerrado en las bibliotecas" es un tanto incierta, pues se entiende: 1) que Ramírez hizo uso de otros espacios bibliotecarios queretanos y no solamente de aquella biblioteca conventual, herencia de la Colonia, o 2) que la biblioteca de San Francisco estaba constituida, en el tiempo que la consultó, por otros acervos que habían pertenecido a otras bibliotecas monacales. Ante la carencia de bibliotecas públicas en esa ciudad, Ramírez utilizó los fondos bibliográficos que tuvo a su alcance.

Se tiene noticia de que desde su juventud supo valorar el servicio de lectura como esencia del servicio bibliotecario. Al respecto Altamirano, quien fue su discípulo en el Instituto Literario de Toluca, escribió sobre Ramírez:

Su sed de saber era inmensa, y para satisfacerla se consagró, tanto en la excelente biblioteca anexa al Colegio de San Gregorio, como en la de la Catedral y en otras que había entonces, a una lectura constante, apasionada, mortal, por espacio de ocho años consecutivos, sin concederse la menor distracción, lo cual hizo que se contara entre sus colegas, que habiendo entrado en esas bibliotecas erguido y esbelto, salió de ellas encorvado y enfermo; pero erudito y sabio, eminentemente sabio. ${ }^{23}$

Los libros vedados -legado cultural y sociopolítico del yugo colonial- lo atrajeron enormemente; tomemos en cuenta que su padre fue un lector de libros prohibidos, por lo que su acercamiento a esta naturaleza de lecturas data desde su niñez. En tiempos del virreinato era común que las principales bibliotecas institucionales tuvieran una sección especial dedicada a este tipo de acervos, y la Biblioteca de la Catedral Metropolitana no sería la excepción. Al respecto, Gastón García Cantú comenta que "Guillermo Prieto reconoció [...] al lector asiduo de Quevedo y D’Alembert y una inapreciable ironía volteriana: al joven formado en el fondo prohibido de la biblioteca de la Catedral, a la que accedió como dependiente gratuito por la complicidad del Padre Cortina; aprendizaje del cual salió como lo vería el mundo de su época: El Nigromante". ${ }^{24}$

\footnotetext{
${ }^{23}$ Ignacio Manuel Altamirano, "Biografía de Ignacio Ramírez", en Obras de Ignacio Ramírez, t. 1 (México: Oficina Tip. de la Secretaría de Fomento, 1889), xi.

${ }^{24}$ Gastón García Cantú, "El Nigromante", en La República de las Letras: asomos a la cultura escrita del México decimonónico. Volumen III: Galería de escritores, ed. de Belem Clark
} 
Sin duda, en el contexto del siglo XIX referente a la historia sobre la lectura de libros vedados por la Iglesia católica, habrá que incluir la figura del lector reformista que nos ocupa. Concretamente, en relación con la historia de la censura represiva de "textos políticos-filosóficos que atacaban al poder absoluto de los reyes y de la Iglesia", esto es, "textos antimonárquicos y antieclesiásticos", ${ }^{25}$ libros que se asocian con relevantes transformaciones sociales, políticas, culturales e ideológicas en América, entre ellas el movimiento de Reforma en México.

Gracias a Altamirano -quien cita el discurso pronunciado por Hilarión Frías y Soto relativo al ingreso de Ramírez como socio de número a la Academia de Letrán- sabemos que éste, "abstraído en el estudio, recorría las bibliotecas públicas porque no podía tener libros, y leía todo, y todo lo absorbía, asimilándose una gran dosis de ciencia, con esa selección de los talentos superiores que extractan la doctrina, desechan lo excedente y lo falso, concretan, y sobre los conocimientos adquiridos implantan sus propias deducciones". ${ }^{26}$

La práctica de la lectura en las mejores bibliotecas que Ramírez pudo consultar, durante sus años de formación académica y autodidacta, es parte fundamental de los testimonios que se conocen en relación con los momentos que vivió de intenso y habitual estudio. Su quehacer intelectual entre importantes colecciones bibliográficas muestra que supo valorar en su justa dimensión -como educando, lector y usuario- la necesidad de contar con un eficaz "servicio colegial de biblioteca" en particular, y la oportunidad de tener acceso público a otras importantes bibliotecas, en términos generales. Al respecto, se sabe que cuando estudió en el Colegio de San Gregorio:

se aislaba de su grupo de amigos con la finalidad de visitar todas las tardes y fines de semana las maravillosas bibliotecas que existían [en la Ciudad de México], y para que no lo regañara el rector Juan Rodríguez Puebla le entregó una libreta en la que se anotaba la fecha y el sello del día de la biblioteca que visitaba, como control del rector del Colegio de San Gregorio, libreta que Ignacio Manuel Altamirano atesoró toda su vida. ${ }^{27}$

de Lara y Elisa Speckman Guerra, AI Siglo XIX. Ida y Regreso, 205-229 (México: UNAM, IIFI, Centro de Estudios Literarios, 2005), 209.

${ }^{25}$ Cristina Gómez Álvarez y Guillermo Tovar de Teresa, Censura y revolución: libros prohibidos por la Inquisición de México (1790-1819) (Madrid; México: Trama Editorial / Consejo de la Crónica de la Ciudad de México, 2009), 63-64.

${ }^{26}$ Altamirano, "Biografía de Ignacio Ramírez", xvi-xvii.

${ }^{27}$ Arellano, Ignacio Ramírez, 49-50. 
Así, lo reconocemos como un estudiante responsable, sistemático, riguroso, curioso y virtuoso que compaginó el estudio de idiomas con el aprendizaje de diversas ciencias. De tal manera que su vehemencia por adquirir una gran gama de conocimientos, mediante el uso de los mejores servicios bibliotecarios disponibles en la ciudad capital, sorprendió a quienes lo llegaron a conocer.

Con asombro llegó a oídos de Juan Rodríguez Puebla que su alumno Ignacio Ramírez había agotado su libreta de control tres meses después de que se la había entregado. Así, visitó las bibliotecas referidas y con orgullo verificó que había leído diversos volúmenes de todo tipo de ciencias y doctrinas, por lo que reunió a los científicos y catedráticos para examinar al joven Ignacio Ramírez, a fin de comprobar si en efecto había estudiado las ramas del conocimiento que afirmaba ya dominar. Lo evaluaron en jurisprudencia, latín, sánscrito (que dominó como lengua extinta), francés, náhuatl, botánica, astronomía, economía, filosofía, literatura, liberalismo progresista, historia, álgebra, teología (fue un analista estricto de la materia) y diversos temas sociales. ${ }^{28}$

A partir de entonces se le consideró, frente a sus examinadores y compañeros, como persona estudiosa y culta, erudita en toda la extensión de la palabra. Las constantes y prolongadas jornadas de estudio y análisis entre libros y bibliotecas lo habían formado para llegar a ser uno de los principales intelectuales del liberalismo mexicano; un liberal puro y probo que habría de pensar y actuar, en congruencia con sus ideales, para estatalizar la Biblioteca Palafoxiana y crear de modo decisivo la Biblioteca Nacional de México.

Además de la Biblioteca del Colegio de San Gregorio y la de la Catedral Metropolitana, ¿qué otras importantes bibliotecas tuvo Ramírez a su alcance? Es probable que también usara la Biblioteca del Colegio de San Juan de Letrán, la de la Universidad de México y la del Colegio de San Ildefonso. En ese contexto cultural bibliotecario aún no existía el servicio oficial de una biblioteca nacional, si bien desde 1833 había comenzado el esfuerzo gubernamental por crearla, mediante el decreto atribuido al presidente Valentín Gómez Farías. ${ }^{29}$

\footnotetext{
28 Ibid., 50.

${ }^{29}$ Véase el texto del decreto en "Octubre 26 de 1833", donde se decide que "se establece en la ciudad federal una biblioteca nacional" y se dan los detalles de la composición de sus fondos, en María del Carmen Ruiz Castañeda, Luis Mario Schneider y Miguel Ángel Castro, comps. y eds., La Biblioteca Nacional de México. Testimonios y documentos para su historia (México: UNAM, IIB, BN, 2004), 519-523.
} 
Como mencionamos, a partir de 1845 Ramírez comenzó su vida literaria y periodística, y el conocimiento adquirido entre libros y bibliotecas iba a resultarle esencial en las diferentes esferas de su vida intelectual. Los datos que sobre él conocemos reafirman la idea de que: "La relación que los hombres de la Reforma tuvieron con los libros es impresionante", pues fueron "generaciones de amplias lecturas, realizadas en ricas bibliotecas y ávidas de un sentido universalista nada común". ${ }^{30}$

\section{El conocimiento enciclopédico, fruto de su empeño autodidacta}

Con base en estos antecedentes, que denotan su dedicación y amplios y admirables conocimientos en diversas ramas, al tiempo que muestran su metodología autodidacta, puede afirmarse que Ramírez destacó no solamente como alumno de importantes instituciones educativas: constituye un modelo de vida intelectual que muestra el poder del incipiente servicio de biblioteca al público, esencia que comenzaría a delinear el perfil de lo que serían las primeras bibliotecas públicas mexicanas en las postrimerías del siglo XIX.

La polémica composición literaria que leyó ante los miembros de la Academia de Letrán la tituló No hay Dios. Pese a la oposición que presentaron algunos a que fuera leída, obtuvo la autorización para hacerlo. En los momentos del debate mostró saber de memoria autores grecolatinos y estar familiarizado con lecturas de enciclopedistas como Voltaire y D'Alembert. Entre exclamaciones de horror, réplicas y muestras de admiración y aplausos, fue aceptado en "el primer centro docto donde se elaboró una literatura consciente", ${ }^{31}$ cuyas reuniones se efectuaban en la "librería" del Colegio de San Juan de Letrán. ${ }^{32}$ Es decir que la Academia sesionaba en la biblioteca del colegio homónimo, la cual "alcanzaba a 7414 títulos". ${ }^{33}$

Los conocimientos científicos y literarios de Ramírez se reflejaron tanto en la prensa como en la tribuna. Artículos, libros y discursos cívicos son testimonio

\footnotetext{
${ }^{30}$ Ernesto de la Torre Villar, Prólogo a La biblioteca de un reformador, de José Herrera Peña (Morelia: UMSNH, 2005), 15, 23.

${ }^{31}$ Alicia Perales Ojeda, Asociaciones literarias mexicanas: siglo XIX (México: UNAM, Centro de Estudios Literarios, 1957), 51.

32 Marco Antonio Campos, "La Academia de Letrán", Literatura Mexicana 8, núm. 2 (1997): 581.

${ }^{33}$ Osorio y Berenzon, "Biblioteca Nacional de México", 328.
} 
claro del grado de empoderamiento que le proporcionaron los libros y bibliotecas en las esferas de la política, las ciencias y las letras.

En el ámbito político, la República representativa, democrática y federal exigía la formulación de políticas progresistas que no solamente estuviesen basadas en determinados principios y valores, sino también en el saber adquirido por los prohombres de la Reforma.

La defensa de la República no sólo se llevó a cabo en los sangrientos campos de batalla, también se realizó mediante la brillante contienda de ideas impresas en periódicos, revistas y libros. La libertad de imprenta y de cultos, la separación de la Iglesia y el Estado, la confiscación de los fondos de las bibliotecas del clero regular y secular, la creación de nuevas instituciones públicas, la demolición del monopolio económico y educativo de la Iglesia, la alfabetización y educación del pueblo, las intensas luchas entre los conservadores y liberales, la independencia social y política definitiva, al igual que otros asuntos de políticas reformistas, debieron demandar especial dominio de una gran variedad de conocimientos.

La dimensión autodidacta de Ramírez está estrechamente relacionada con el mundo de los libros y las bibliotecas, con el universo del hábito de la lectura y con esa permanente curiosidad que lo caracterizó en las diferentes etapas de su vida intelectual. Su rasgo de aprender nuevos y más conocimientos mediante su propia inquietud y curiosidad se fue afianzando de acuerdo con sus variados e inusuales intereses.

Esta práctica de estudio y análisis le permitió, sin duda, reflexionar en torno al papel de la educación en la sociedad, a sobresalir en su labor docente y convertirse en un destacado propulsor de la educación formal e informal, así como en divulgador de la ciencia y notable autor de notas, artículos y libros de texto. Como "hombre de letras", su nombre sobresale en la historia de la literatura mexicana, concretamente en la esfera de la "literatura política". ${ }^{34}$ Sus Lecciones de literatura muestran que, asimismo, incursionó en la valoración intelectual y estética del arte en torno a la expresión de la palabra, la "bella literatura", formada por la poesía y la elocuencia.

Ramírez logró adquirir, mediante la lectura crítica de impresos y la consulta asidua en bibliotecas, un inconmensurable arsenal de conocimientos que le permitieron ayudar a gobernar el país y redactar gran cantidad de escritos que hoy 34 Julio Jiménez Rueda, Historia de la literatura mexicana, 6a. ed. (México: Ediciones Botas,
1957), 260-261. 
pueden ser de gran importancia para los historiadores, sociólogos, pedagogos, literatos y otros especialistas interesados en temas del México decimonónico.

La biografía intelectual de Ignacio Ramírez es uno de los testimonios que evidencia con claridad la versatilidad de su vida y obra. Sus Obras completas y las diversas antologías que sobre sus escritos han salido a la luz, son muestras fehacientes en este sentido.

La cantidad y diversidad de material periodístico del que se sirvió para generar información, debate y opinión pública son también claras muestras del conocimiento enciclopédico que cultivó y publicó, respaldado por la libertad de imprenta, y de prensa en particular. Libertades que oscilaron, según el gobernante en turno, entre la amplia propagación o la severa limitación de su ideología. Ramírez alternaba su trabajo con la cárcel, a punto de convertirse en su segundo hogar por lo mucho que era recluido debido a que sus ideas -como las de Francisco Zarco- desencadenaban desafiantes acciones en el bando liberal y producían peligrosas reacciones entre los conservadores.

Si el conocimiento enciclopédico de Ramírez se sostuvo gracias a la práctica autodidacta de la lectura, llevada a cabo en relevantes acervos en el contexto bibliotecario decimonónico de la Ciudad de México, entonces él fue un nato librepensador, un hombre ilustrado, culto, escéptico, radical, progresista y laico.

Por otra parte, cabe aclarar que pudo haber sido un gran coleccionista de valiosos y bellos libros, a través de la política referente a la nacionalización de los bienes del clero y a la oportunidad que tuvo de poseer importantes joyas bibliográficas de las bibliotecas conventuales expropiadas, sin embargo no atesoró libros para emprender el desarrollo personal de una colección selectiva, de tal manera que el apelativo de "bibliófilo" resulta inadecuado en su caso; el que sí se le puede atribuir es el de "lector multidisciplinario", por abarcar sus intereses varias materias o temas.

Su vehemencia por los libros y los periódicos, su inclinación por las bibliotecas y pasión por la lectura son asuntos indiscutibles sobre los que se cimenta su perfil autodidacta y enciclopédico. No en balde, al poco tiempo de su muerte, fue considerado el "sabio mexicano" que vivió la "transición del antiguo al nuevo régimen". 35

${ }^{35}$ Francisco Sosa, Biografías de mexicanos distinguidos (México: Oficina Tip. de la Secretaría de Fomento, 1884), 854. 


\section{Pensamiento y acción en torno a los libros y la lectura}

Además de reflexionar sobre la literatura, al hacer suyas las causas de los libros y la lectura, Ramírez pensó en una serie de propuestas que giraron en torno a la problemática que entrañaba el influjo de la Instrucción pública, fundamento del valor de la educación pública del pueblo mexicano para la conformación de una nueva república democrática. De esta manera, descolló sobre varios asuntos, entre los que destacan la instrucción en las escuelas primarias, la educación indígena y de las mujeres, los libros de texto y la educación en los municipios. Concibió como una "necesidad que se publiquen, no una vez, sino continuamente obras elementales... libros originales", 36 impresos que complementaran las obras de consulta o referencia. Es decir,

nuevos métodos y nuevos ensayos para que la enseñanza sea más fácil y para que las obras elementales representen microscópicamente los adelantamientos admirables de la ciencia. Reproducen en pequeño lo que las enciclopedias en grande. Lo que antes se llamaba cartilla y se transformó en silabario, hoy es una enciclopedia que comprende no solamente los elementos naturales del lenguaje, sino representa fielmente los objetos, y hablando al oído y a la vista, inicia al educando en los objetos fecundos de la historia natural y de las artes. Diccionarios siguen al través de todas las naciones y de todos los siglos la historia de cada palabra, descomponiéndola en sus más imperceptibles elementos. ${ }^{37}$

También se preocupó por las publicaciones de las imprentas capitalinas, como la de Manuel Murguía, que a su juicio imprimía "libros envejecidos y estampas ridículas", pues se trataba de figuras religiosas que mantenían a millones "extraviados en el país de las quimeras". Por ello era menester elaborar "¡Libros, periódicos, catecismos, cartillas, mapas y estampas para el pueblo!". Una producción bibliográfica que resumiese los avances de las diferentes ciencias, pues en tanto "esta necesidad no se cubra siquiera a medias, jno seremos gente de razón los mexicanos!". ${ }^{38}$

\footnotetext{
${ }^{36}$ Ignacio Ramírez, Obras de Ignacio Ramírez, t. 2 (México: Oficina Tip. de la Secretaría de Fomento, 1889), 179-195.

${ }^{37}$ Ibid., 190.

38 Ibid., 190-192.
} 
Dada la visión que tuvo de los indígenas, en especial sobre la importancia de su instrucción y educación, fue categórico ante la falta de material bibliográfico para ellos en sus idiomas. Un punto de vista adelantado a su tiempo, si tenemos en cuenta que la atención en torno al asunto de libros escritos y publicados en lenguas autóctonas sigue siendo hoy en día insuficiente en los contextos culturales indígenas de México. Para Ramírez, la instrucción a los indígenas debía ser la base de la "verdadera educación pública". De poco o nada servía enseñarles lectura, escritura y aritmética si pasado el tiempo las olvidaban "por no tener qué leer, qué escribir, qué contar". Su idea era que se formaran como ciudadanos responsables de sus actos y fueran partícipes, con base en los derechos del pueblo, en el marco de una sociedad democrática, "deliberante y soberana". 39

El tema de los libros de texto, destinados a la educación de la niñez, también fue de su singular interés. Consciente del legado educativo colonial, opinaba que "los libros que sirven de texto en las escuelas, donde, por cuenta de la autoridad, se reparte la instrucción a los niños: de esas obras, unas son heredadas de la época colonial... Obras de la época española. - Inútil es sujetarlas a una crítica minuciosa; ellas pudieron ser admirables en otro tiempo", ${ }^{40}$ pero no en tiempos de la República. Los libros y la lectura, las escuelas y bibliotecas eran para Ramírez, al igual que para otros célebres liberales como Altamirano, elementos esenciales para adquirir nuevos conocimientos, componentes necesarios de la instrucción pública, con el fin de edificar una gran nación.

Como uno de los adversarios más acérrimos del poder eclesiástico, el Nigromante no omitió pensar en la enseñanza religiosa. En una carta que escribió el 19 de marzo de 1871 a Altamirano, publicada originalmente al día siguiente en El Federalista. Periódico Político y Literario (1871-1878), evidencia su inclinación por la libertad religiosa al criticar el catecismo de Ripalda. Se refería al Catecismo de la doctrina cristiana, del clérigo Jerónimo Martínez Ripalda (15361618), cuya publicación servía a la niñez como libro de texto, material utilizado no sólo para la enseñanza cristiana, sino también para aprender materias como español, civismo y la práctica de lectura.

Tratándose de un impreso de tiempos del yugo español, caracterizado por la hegemonía del clero en materia educativa, se entiende que en las escuelas primarias se estudiara la herencia concerniente a la doctrina cristiana, por lo que debido a la escasez de libros, los educandos continuaban utilizando -en pleno

\footnotetext{
39 Ibid., 183-184.

40 lbid., 189-190.
} 
auge reformista y republicano- como texto de lectura ese catecismo, "probablemente el libro con el mayor número de ediciones durante todo el periodo colonial". ${ }^{41}$ Ante tal circunstancia, Ramírez opinaba que esa obra plagada de prescripciones religiosas y dogmas que el clero sabía explotar, en concordancia con sus intereses y fueros, era un libro que condenaba a la multitud infantil a la ignorancia, por ello declaró inútiles esos métodos y libros.

El influjo de la práctica de lectura basada en ese catecismo y su uso como libro de texto a lo largo del tiempo puede aquilatarse con la siguiente aseveración: "La supervivencia del mismo catecismo durante más de trescientos años dice bastante de su aceptación entre el clero, su eficacia como texto de instrucción elemental y su influencia en la formación de muchas generaciones de españoles, novohispanos y mexicanos". ${ }^{42}$ Ese texto era parte de esos "libros envejecidos" a los que aludía Ramírez, inútiles para ilustrar al pueblo, obras fútiles para construir la ciudadanía.

Tal perspectiva fue apreciada por Altamirano al concebir que fuera la instrucción la que diera grandeza a la República, una estructura política que, más que sabios, necesitaba de ciudadanos que supieran leer y escribir. ${ }^{43}$ En la dura pugna entre conservadores y liberales, los libros y periódicos fueron objetos fundamentales en la histórica batalla de ideas originada durante el movimiento de Reforma.

Conocer someramente la situación de la educación pública que prevalecía y la naturaleza del material bibliográfico en que se apoyaba la labor de los maestros rurales y urbanos permite comprender mejor la disposición y el empeño de Ramírez por elaborar libros de texto, concebidos para la enseñanza en las escuelas básicas, tanto urbanas como rurales. En cuanto a la obra titulada Libro rudimental y progresivo para la enseñanza primaria, la escribió en 1873 por encargo del funcionario público Luis Malanco. Referida a veces como Libro rudimental y progresivo, en su "Breve noticia sobre el origen de estos libros", Francisco Sosa advirtió:

${ }^{41}$ Dorothy Tanck de Estrada, "La enseñanza de la lectura y la escritura en la Nueva España, 1700-1821", en Historia de la lectura en México: Seminario de Historia de la Educación en México, coord. de Josefina Zoraida Vázquez (México: Ediciones del Ermitaño / El Colegio de México, 1988), 71.

42 Pilar Gonzalbo Aizpuru, "La lectura de evangelización en la Nueva España", en Historia de la lectura en México: Seminario de Historia de la Educación en México, coord. de Josefina Zoraida Vázquez (México: Ediciones del Ermitaño / El Colegio de México, 1988), 35.

${ }^{43}$ Ignacio Manuel Altamirano, "Crónica de la Semana", El Renacimiento. Periódico Literario 1, 1 de enero de 1889: 19. 
Haremos, sí, notar que para nosotros el inapreciable valor de estos libros consiste en que sin fatigar la inteligencia del niño le inicien en el conocimiento de las ciencias que más tarde profundizará; de manera que al salir de la escuela primaria se encuentre en posesión de todo un caudal de ideas que le facilite la adquisición de las que han de constituir su instrucción superior, su profesión artística, científica o literaria. ${ }^{44}$

La vida intelectual de Ramírez está estrechamente vinculada al Instituto Científico y Literario de Toluca. En virtud de la enseñanza que impartía con juicio crítico a sus educandos -basada en los libros básicos que él mismo había procurado elaborar con especial esmero-, la reacción del clero local no se hizo esperar. Al apartarlo de la enseñanza laica y gratuita, también lo separaron de sus libros. Como en los tiempos inquisitoriales, el clero toluqueño mostró su intolerancia ante el acceso al saber.

La agresiva reacción de un sector que había predominado durante siglos fue el precio que tuvo que pagar Ramírez, pues la transición del antiguo al nuevo régimen aún faltaba por alcanzarse mediante grandes sacrificios políticos y sociales. Las ideas de aquel profesor liberal serían presa de intrigas del añejo conservadurismo, de la intransigencia y fanatismo clerical, hasta el punto que lograron alejarlo tanto de las aulas de esa entidad educativa como de sus apreciados libros. Igual que en los oscuros tiempos de la Colonia, su material bibliográfico sería conducido al fuego, hasta convertirlo en cenizas. Pero no sería el único amargo momento que vivió en su mundo de enseñanza y aprendizaje, de libros y lecturas.

En 1853, tiempos del funesto presidente Antonio López de Santa Anna (1794-1876), Ramírez fue invitado a impartir la clase de literatura en un colegio políglota que había fundado Felipe Sánchez Solís (1816-1882), ilustre educador y político liberal. Cabe mencionar que, siendo director del Instituto Científico y Literario de Toluca, Sánchez Solís fue quien recuperó "la biblioteca que recibieron los alumnos Ignacio M. Altamirano y Joaquín M. Alcalde"45 de esa entidad educativa. Sánchez también fue director del Colegio de la Paz y del de San Francisco.

\footnotetext{
${ }^{44}$ Francisco Sosa, Introducción a Libro rudimental y progresivo para la enseñanza primaria, de Ignacio Ramírez (México: Oficina Tip. de la Secretaría de Fomento, 1884), ii-iii.

${ }^{45}$ Hugo Aranda Pamplona, Biobibliografía de los escritores del Estado de México (México: UNAM, IIB, 1978), 92.
} 
En ese contexto docente, y dada su dedicación como maestro de literatura, Ramírez volvió a vivir momentos de intolerancia, pero ahora por parte de Su Alteza Serenísima, como se hacía llamar el dictador López de Santa Anna. El temor de ese gobernante por aquel "sabio profesor" hizo que lo mandara a prisión.

En el mismo periodo, la Biblioteca del Instituto Científico y Literario de Toluca sería atacada, a causa del plebiscito que llevó a cabo Santa Anna para que el pueblo aprobase su reelección. Puesto que una parte del alumnado en edad para votar expresó su negativa, la represión se hizo patente. Al grito de "¡Mueran las ciencias y las artes!", un destacamento militar llegó hasta la escuela durante la noche de los comicios. En ese clima de intimidación, la represión recayó no solamente en los estudiantes, sino también sobre los libros: la autoridad escolar mandó incinerar los que consideró perniciosos para la postura conservadora del Instituto; algunos alumnos votantes fueron expulsados y otros vejados. Eran días en que en esa institución se seguía utilizando el Catecismo de Ripalda y en los que aún intervenían sacerdotes con autoridad docente, como el presbítero José Mariano Dávila.

Las clases sobre el tema que Ramírez impartió debieron inspirarlo para escribir sus Lecciones de literatura. Este libro póstumo de 1884 fue estructurado en siete capítulos, e impreso bajo el sello de la Imprenta de Francisco Díaz de León. Trata sobre el lenguaje humano, el lenguaje fonético, el idioma castellano, la prosa, versificación, belleza literaria y la historia de la poesía española. Hizo comprender que hasta entonces la historia literaria, a través del mundo de las letras (discursos y poesías, prosa y verso), era apenas una especie de enciclopedia en compendio.

De modo que los libros de Ignacio Ramírez ayudaron, en general, a instituir el medio propicio para empezar a forjar una educación laica y gratuita, comenzando así a germinar la enseñanza civil de los futuros ciudadanos. Desde esta perspectiva, Ramírez se esforzó por construir un país civilizado, en provecho de todos los mexicanos.

\section{La obra político-cultural que consolidó la fundación de bibliotecas}

En términos generales, los liberales estuvieron convencidos de la relevancia de la educación. En lo particular, creyeron en dos instituciones esenciales por la manifiesta función social que podían desempeñar, como base de una verdadera 
educación pública: la escuela y la biblioteca. Altamirano aseveró en torno a la primera: "Lo que se necesita en México [...] es abrir escuelas de enseñanza primaria por todas partes, en todos los ámbitos del país, con profusión, con impaciencia, con exageración, si vale hablar así". ${ }^{46}$ Ramírez manifestó, en cuanto a la segunda, que se necesitaba multiplicar las bibliotecas para no entorpecer los estudios debido a la falta de libros. Era una necesidad pública contar con libros y bibliotecas, por ello la insistencia y exigencia de constituir -durante esos azarosos tiempos- la Biblioteca Nacional de México.

De acuerdo con el impulso liberal en materia de escuelas, bibliotecas y libros, estos recursos indispensables debían ayudar a promover tanto la instrucción como la educación. Desde esta perspectiva, Ramírez concibió las bibliotecas como espacios organizados de libros para ponerlos al servicio de la sociedad.

A Ramírez se debe también, como ministro de Justicia, Negocios Eclesiásticos e Instrucción Pública en 1861, la creación de la Biblioteca Nacional de México y la conversión de la Biblioteca Palafoxiana en biblioteca pública. Desde una perspectiva general, se afirma que como funcionario del Ministerio se encargó de fundar bibliotecas, una obra político-cultural ordinariamente omitida o ignorada en la literatura que versa sobre la historia de las bibliotecas mexicanas en general, ${ }^{47}$ y en la historia de la Biblioteca Nacional de México en particular. ${ }^{48}$ Más aún, le correspondió, como político e ideólogo liberal, promover las Leyes de Reforma y luego, en calidad de funcionario público, tuvo la responsabilidad de aplicar y ejecutar esa legislación reformista, cuyo influjo alcanzó el funcionamiento orgánico del incipiente servicio público de biblioteca que surgió en el siglo XIX.

Había llegado el momento de comenzar a hacer realidad la separación de la Iglesia y el Estado; de considerar los centros bibliotecarios entre las nuevas instituciones públicas, democráticas y civilizadoras; de pensar en la creación de nuevos proyectos educativosy culturales. Era necesario defenderla libertad de imprenta y de prensa, para favorecer el interés público, la vida pública de la

${ }^{46}$ Cristina Barros y Catalina Sierra, Ignacio Manuel Altamirano. Iconografía (México: Conaculta / FCE / Gobierno Constitucional del Estado de Guerrero, 1993), 103.

${ }^{47}$ Carmen Vázquez Mantecón, Carlos Herrero Bervera y Alfonso Flamenco Ramírez, Las bibliotecas mexicanas del siglo XIX (México: SEP, DGB, 1987); Ramiro Lafuente, Un mundo poco visible: imprenta y bibliotecas en México durante el siglo XIX (México: UNAM, 1992); Osorio y Berenzon, "Biblioteca Nacional de México".

${ }^{48}$ Luis González Obregón, La Biblioteca Nacional de México, 1833-1910. Reseña histórica (México: [s. e.], 1910); Rafael Carrasco Puente, Historia de la Biblioteca Nacional de México (México: SRE, Departamento de Información para el Extranjero, 1948). 
nación y el desarrollo de las ciencias y artes. Ideas cardinales que tanto defendió otro escritor, periodista y político liberal de la Reforma: Francisco Zarco (1829-1869), cuyo pensamiento y acción en torno a estos asuntos fundamentales, tan radicales como la postura de Ignacio Ramírez, pueden constatarse a través de sus textos publicados en algunos periódicos liberales como El Demócrata y El Siglo Diez y Nueve. ${ }^{49}$

La base progresista del Nigromante, en relación con la Biblioteca Nacional como principal repositorio bibliográfico de la nación, y la Biblioteca Palafoxiana, una de las principales bibliotecas clericales de la época, fue el conjunto de avanzadas ideas liberales que forjó en materia de educación pública, laica, obligatoria y gratuita. Asimismo, su convicción política en torno a la separación de la Iglesia y el Estado debió influir para determinar y concordar que las bibliotecas clericales y conventuales de origen novohispano pasaran a formar parte de la Biblioteca Nacional y que la Palafoxiana se convirtiese en biblioteca pública del estado. Había que superar el rezago en que se encontraba la nación mexicana en cuanto a instituciones públicas, incluyendo la apertura de bibliotecas.

Como resultado de la voluntad política de Ramírez, apuntalada en la Ley de Nacionalización de Bienes Eclesiásticos, expedida por el presidente Benito Juárez el 12 de julio de 1859, el fondo de origen de la Biblioteca Nacional quedó constituido por algunas de las principales bibliotecas que pertenecieron a las comunidades clericales (regulares y seglares) de la Nueva España. Entre las del clero regular cabe recordar las que habían dependido de los conventos de San Francisco, San Agustín, La Merced y del Colegio de San Fernando. Del orden secular destacan la Biblioteca de la Catedral Metropolitana y la de la Real y Pontificia Universidad de México.

Dicha obra, subrayamos, no ha sido cabalmente reconocida en los antecedentes históricos de la máxima institución bibliotecaria de México. ${ }^{50} \mathrm{La}$ misma omisión ha sucedido con la conversión de la Biblioteca Palafoxiana en biblioteca estatal. ${ }^{51}$ La figura histórica de este personaje no sólo ha sido suprimida de la historia nacional, sino también omitida e ignorada en la esfera de

\footnotetext{
${ }^{49}$ Francisco Zarco, Escritos sobre la libertad de imprenta (México: Conaculta, 2013).

50 Juan Bautista Iguíniz, "La Biblioteca Nacional de México", Revista de Historia de América 8 (1940); Osorio y Berenzon, "Biblioteca Nacional de México"; Ruiz Castañeda, La Biblioteca Nacional de México: testimonios.

${ }^{51}$ Amado Manuel Cortés, "La transformación de una biblioteca colonial a una biblioteca liberal", en Del manuscrito a la imprenta, el nacimiento de la librería moderna en la Nueva España: la Biblioteca Palafoxiana (México; Puebla: Ediciones Eón / BUAP, 2012), 211-218.
} 
la historia mexicana en torno a las bibliotecas decimonónicas que comenzaron a desarrollarse en el contexto de la corriente ideológica del liberalismo y del movimiento de Reforma.

Una publicación reciente menciona el aporte de Ignacio Ramírez en materia de instituciones bibliotecarias. En ella, se reconoce a este liberal como uno de los principales interesados por hacer funcionar la Biblioteca Nacional de México. En efecto, en el libro que narra la historia de esta institución entre 1822 y 1929, la autora asevera:

Al conocerse el nombramiento de Ignacio Ramírez [como ministro de Justicia e Instrucción Pública], de inmediato se volvió a retomar el tema de las bibliotecas, seguramente porque se sabía de su interés en ellas, y el ministro pondría mayor atención a los reclamos sociales que hacían respecto a su existencia. No se equivocaron, pues el 23 de enero [de 1861], día en que tomó posesión de su cargo, suprimió la Universidad y reabrió la Biblioteca Nacional, de acuerdo con lo establecido en la disposición de 1857 [...] sobre las bibliotecas [conventuales] abandonadas, ordenó su recuperación. ${ }^{52}$

La Biblioteca Nacional de México en tiempos del movimiento de Reforma no es solamente objeto de estudio de la historiografía de las bibliotecas mexicanas del siglo XIX, también es tema de análisis de la historia de la educación en México en tiempos de Juárez. La propensión de Ramírez por los centros bibliotecarios permite entrever lo que debió vislumbrar como política de educación en cuanto a crear bibliotecas dirigidas al público en general, por un lado, y establecer escuelas de naturaleza pública, por el otro. Acorde con su apego por la lectura e instrucción abierta, mostró su apoyo para reabrir la "Biblioteca Nacional con la idea de que no podía existir una instrucción pública sin bibliotecas; además de considerar la oportunidad de volver públicas las librerías del clero al incorporarlas a la Nacional [...] asimismo, emprendió acciones decisivas para su organización, sin olvidar lo efectuado con anterioridad".53

La creación de lo que debería ser hoy en día la institución preponderante del sistema bibliotecario mexicano tuvo un proceso dilatado a partir de 1833, año en que Valentín Gómez Farías, en su calidad de vicepresidente de la repú-

\footnotetext{
52 Sofía Brito Ocampo, La Biblioteca Nacional de México: $1822-1929$ (México: UNAM, IIB, 2017), 85.

53 lbid., 85-86.
} 
blica, decretaría el 24 de octubre lo conducente para establecerla. Pero ese proyecto liberal no continuó porque en julio de 1834 Santa Anna anuló lo dispuesto. No obstante, mediante ese primer intento oficial se formuló la necesidad político-social de contar con una institución bibliotecaria republicana que se hiciese cargo de desarrollar, conservar y preservar el patrimonio bibliográfico nacional, y así comenzar a demoler el monopolio bibliotecario de la lglesia y transferir al Estado la responsabilidad política de lo que debía ser la principal institución bibliotecaria de la nación en la naciente república.

La crisis política que enfrentó el Estado mexicano, derivada principalmente del recio enfrentamiento ideológico entre conservadores y liberales, dificultó que otros decretos posteriores para formar la Biblioteca Nacional lograsen el deseado éxito, entre ellos los de 1846 y 1857 . Ignacio Ramírez se encuentra entre los personajes, como José María Luis Mora (1794-1850), Manuel Eduardo de Gorostiza (1789-1851), José María Irigoyen (1807-1840), Valentín Gómez Farías (1781-1858) y José María Lafragua (1813-1875), que concibieron de una manera u otra la creación de esa institución. El Nigromante es uno de los protagonistas que, entre 1833 y 1867, fraguaron, proyectaron y fundaron la Biblioteca Nacional de la república, pues en 1861, siendo miembro del gabinete del gobierno juarista, colaboró en la gestión gubernamental para tal efecto. Como impulsor, promotor o fundador de la Biblioteca Nacional de México, a Ramírez se debe la decisión final de conformar el Fondo de Origen de esta institución, cuya sede final fue el templo de San Agustín. Al respecto, sabemos que:

Ramírez no se limitaba a hacer las leyes, sino que incluso se ocupaba en comprobar si se cumplían o no [...]. Días después se enteró por medio de El Siglo Diez y Nueve de que las bibliotecas de algunos conventos estaban enteramente abandonadas, y los libros y manuscritos a merced del robo. Inmediatamente dictó órdenes para que estos materiales se depositaran en el edificio que sería la nueva Biblioteca Nacional. ${ }^{54}$

Esa nota periodística sin autoría tiene especial valor histórico porque se informaba a la sociedad en general y a Ramírez en particular sobre el estado deplorable en que estaban los acervos bibliotecarios conventuales. Denuncia hecha al poco tiempo de haber sido decretada en Veracruz (12 de julio de 1859)

\footnotetext{
${ }^{54}$ Maciel, Ignacio Ramírez: ideológo, 112.
} 
la Ley de nacionalización de los bienes eclesiásticos, que en su artículo 12 determinaba: "Los libros, impresos, manuscritos, pinturas, antigüedades y demás objetos pertenecientes a las comunidades religiosas suprimidas, se aplicarán a los museos, liceos, bibliotecas, y otros establecimientos públicos". ${ }^{5}$ He aquí la advertencia y amonestación que apareció en El Siglo Diez y Nueve:

bibliotecas. - Se nos ha informado que las de algunos conventos de religiosos enclaustrados están enteramente abandonadas; sus puertas, así como las de los mismos conventos, abiertas, y los libros y manuscritos a merced de todo el que quiera llevárselos. Uno de nuestros colaboradores, que ha estado ayer en el convento de San Agustín ha visto que su biblioteca se encuentra en ese estado, multitud de libros destrozados, esparcidos por los claustros y celdas, otros tirados en el suelo de la biblioteca, en el más completo desorden, y toda ella en un estado tal, que manifiesta claramente que está entregada al pillaje. ¿Qué hacen los señores comisionados para recoger esas bibliotecas? ¿Qué hacen las autoridades que no remedian tan escandaloso desorden? ¿Hemos vuelto a los tiempos de la barbarie, que así se desprecian esos ricos tesoros de la ciencia, y se entregan a la rapacidad de quien quiere pillarlos o destruirlos? Llamamos la atención del Sr. ministro de justicia e instrucción pública sobre un desorden tan vergonzoso para la nación. ${ }^{56}$

La creación de la Biblioteca Nacional de México como fruto de la Reforma fue posible sólo cuando "los enemigos de las instituciones democráticas" dejaron de entorpecer u obstaculizar "la realización de un proyecto tantas ocasiones frustrado". Ramírez, en su calidad política de ministro de Justicia, Instrucción Pública y Fomento del gobierno liberal, fue quien logró consumar la política de conservación de aquellos libros que se debían atesorar "en una biblioteca del carácter de la Nacional", para así resguardar "obras colosales, entre las que se encuentran verdaderas joyas bibliográficas". ${ }^{57}$

\footnotetext{
${ }^{55}$ Manuel Dublán y José María Lozano, comps., "Ley de nacionalización de los bienes eclesiásticos", en Legislación mexicana, ó colección completa de las disposiciones legislativas expedidas desde la independencia de la República, ed. oficial, t. VIII (México: Imprenta del Comercio, de Eduardo Dublán y Chávez, a cargo de M. Lara hijo, 1877), 681.

56 "Noticias nacionales. Bibliotecas", El Siglo Diez y Nueve, 6a. época, año XXI, t. 1, núm. 27, 10 de febrero de 1861: 4.

57 José María Vigil, "Informe del director", en Inauguración de la Biblioteca Nacional de México, abril 2 de 1884 (México: Imprenta de Ireneo Paz, 1884), 10-11, 14.
} 
Sin embargo, la política de conservación de los fondos bibliográficos coloniales no fue simple de cumplir. La ignorancia, el descuido y desorden de unos y la depravación, codicia y el hurto de otros, dificultó en extremo la realización cabal de aquella gestión reformista. El daño ocasionado al caudal bibliográfico, manuscrito e impreso fue considerable; fueron los tiempos del acopio de libros, no siempre lícito, por parte de connotados historiadores, bibliógrafos, libreros, editores y bibliófilos, tanto mexicanos como extranjeros.

En contraste, entre los rasgos característicos de Ramírez cabe destacar su "acrisolada honradez". Cuando se desempeñó como secretario de Justicia, Instrucción Pública y Fomento, se sabe que tuvo la responsabilidad de gobernar grandes cantidades de dinero, joyas bibliográficas y obras de arte. Sobre los libros y cuadros Francisco Sosa, biógrafo también de Ramírez, escribe: "Él, tan ardiente cultivador de los estudios históricos, no tomó un solo libro de los millares sacados de las bibliotecas de las órdenes religiosas; él, amante y conocedor de las obras pictóricas, no llevó a su casa uno solo de los magníficos cuadros extraídos de los claustros". 58

Ignacio Ramírez ha pasado a la historia como un entrañable ejemplo de probidad en el ejercicio de la vida pública del México decimonónico; un modelo de hombre íntegro que supo respetar los bienes públicos de la nación, los cuales permitieron formar diversas instituciones que continúan funcionando y evolucionando, por ejemplo la Biblioteca Nacional de México, o que siguen manteniéndose a través del proceso de conservación, como la Biblioteca Palafoxiana en la ciudad de Puebla.

La obra político-cultural de Ramírez puede sintetizarse en cierto sentido mediante la tríada "lectores, lectura y bibliotecas", con la que pretendió apuntalar la libertad de los miembros de la sociedad dentro del contexto ideológico de la República. Aprender a leer exigió afianzar la edición de libros y el establecimiento y organización de bibliotecas, además de escuelas. Los nuevos servicios bibliotecarios, adheridos a la política reformista, tenían que colaborar para poner fin a los tiempos en que los hombres del incensario se habían encargado, durante tres siglos, de mantener al pueblo alejado de los libros, de cercenar la reflexión científica, de obstaculizar el desarrollo social, político y cultural del pensamiento crítico.

\footnotetext{
${ }_{58}$ Sosa, Biografías de mexicanos distinguidos, 859.
} 


\section{La institucionalización republicana de las bibliotecas}

La Biblioteca Nacional de México es, como se afirma, "una institución de la Reforma", de los tiempos de la República; es el fruto de un nuevo régimen, reconocido como gobierno republicano, formado en el marco de un estado nacional y bajo un orden constitucional. Es obra de proyectos de cultura política estatal llevados a cabo durante tiempos azarosos, cuando la nación políticamente estuvo dividida entre conservadores y liberales, imperiales y republicanos. Acentuemos, en los siguientes párrafos, el espíritu republicano de Ignacio Ramírez en torno a los espacios de lectura pública.

En México, la noción de biblioteca pública como "servicio público" durante el siglo XIX se fue configurando con dificultad en torno a la institucionalidad republicana, pues la herencia colonial en materia de funcionamiento de bibliotecas continuó siendo una pesada carga para transitar del servicio de biblioteca clerical al de biblioteca pública. De tal suerte que la transformación de las bibliotecas coloniales en públicas fue una política importante en el maremágnum del movimiento de Reforma. Las bibliotecas no estuvieron al margen de la discordia y oposición del ala conformada por los ideólogos conservadores e imperialistas. La dualidad conceptual entre la "Biblioteca Imperial" del emperador Maximiliano y la "Biblioteca Nacional" del presidente Benito Juárez ilustra cómo esta institución fue parte de la pugna política entre imperiales y republicanos.

Ramírez luchó por erradicar el monopolio eclesiástico en materia de instituciones bibliotecarias. En el México independiente de la corona española y emancipado del grupo conservador interesado en mantener un orden imperial, los "servicios bibliotecarios religiosos" tenían que convertirse en "servicios bibliotecarios republicanos".

El genuino espíritu de la República, adormecido aún en aquellos tiempos, debía basarse en la instrucción del pueblo, y en este esfuerzo de carácter gubernamental, Ramírez percibió las bibliotecas como instituciones indispensables. En términos generales, se afanó por hacer valer el derecho a la educación, al conocimiento, a la lectura, para comenzar a construir la ciudadanía, elemento esencial de la República que ayudó a forjar.

Tuvo clara la idea de que una de las principales funciones de una biblioteca nacional es conservar el patrimonio bibliográfico de la nación. En torno a la función eminentemente cultural para fomentar la búsqueda, compilación y resguardo de aquellas obras dispersas, escribió con cierta inquietud: "tantos 
libros que se publican sobre diversos ramos" concernientes a la sociedad mexicana, hace necesario reunir "lo que esparcido se encuentra en los campos y en las bibliotecas", 59 manuscritos y libros que facilitaran, en fin, el análisis y estudio de las "antigüedades mexicanas", para posibilitar el trabajo de los historiadores y bibliógrafos.

Por su parte, ante la separación entre la Iglesia y el Estado, la Biblioteca Palafoxiana, en virtud de su naturaleza clerical, no se mantuvo al margen de las Leyes de Reforma: sus bienes bibliográficos debieron pasar al dominio directo de la nación, sin indemnización alguna. Los conceptos de "libros manuscritos", "libros impresos" y "bibliotecas", en calidad de "bienes eclesiásticos", habrían de quedar asentados en dicha ley, configurándose a partir de entonces como "bienes públicos" administrados por el estado laico mexicano.

Con el proceso de la Reforma y el triunfo de la República, Ramírez comenzó, mediante la fundación de bibliotecas, a contribuir en la gestación de una nación libre; a colaborar en la construcción de senderos de libertad para consultar y leer libros más allá de los círculos eclesiásticos; a coadyuvar en el resguardo de la memoria bibliográfica nacional; a propiciar la definitiva constitución del mayor repositorio bibliográfico del país.

Ante la derrota del Imperio y el impulso republicano, nuestro personaje, apoyado en la política gubernamental juarista, otorgó recia solidez a las primeras instituciones bibliotecarias que iniciaron su andadura en el contexto de la República Restaurada. Fue entonces cuando se empezaron a procurar las condiciones con el fin de lograr que México se perfilara hacia la senda de una república de lectores, y para que se convirtiera culturalmente en la República de las Letras. Es decir, una sociedad con la posibilidad de aspirar a conformar una ciudadanía lectora, en la que se distinguieran "hombres bien educados, responsables de sus acciones y miembros de una sociedad deliberante y soberana".60 Una obra de gran calado si pensamos en el entorno real de Ramírez, una república donde la figura de la biblioteca pública aún era difusa y limitada; donde la gestión de genuinas bibliotecas públicas evolucionaría paulatinamente con el fomento de los valores de la república democrática.

Para Ramírez y sus cofrades liberales era esencial controlar todo el legado colonial, por lo que la expropiación de los bienes eclesiásticos, en particular los bibliográficos y bibliotecarios, estuvo en el centro de la política que apuntaba

\footnotetext{
${ }^{59}$ Ramírez, Obras de Ignacio Ramírez, 2: 210.

${ }^{60}$ Ibid., 184.
} 
hacia la conformación de un estado republicano. El triunfo de la República invalidó tanto el modelo de biblioteca conventual como el proyecto de biblioteca imperial, pues con la nacionalización de los bienes del clero se contuvo el dominio eclesiástico de libros y bibliotecas. Al respecto Manuel Payno escribió, a poco tiempo de ser restaurada la República:

Durante la época del Imperio, Maximiliano nombró a un bibliotecario extranjero que tal vez era austriaco, y concibió diversos proyectos para darle otro mejor orden a la biblioteca, reuniendo los libros dispersos y colocándola en otro local; pero en realidad nada se llevó a efecto, y por el contrario, además de gastarse en el crecido sueldo de ese bibliotecario, parece que una buena porción de libros ha padecido extravío, sin que se pueda señalar a punto fijo, quién ha sido el culpable de un descuido tan grave. ${ }^{61}$

Asimismo, es importante considerar el periodo de la Intervención francesa (1862-1867) en tiempos de Juárez, porque en ese lapso se interrumpió bruscamente el trabajo a favor de ciudadanizar las instituciones culturales de la República, como las bibliotecas. Los logros políticos del Plan de Ayutla y de la Guerra de Reforma en cuanto a mantener el orden constitucional, en concordancia con la ideología liberal, se encaminarían a ser destruidos. Sin embargo, el momento clave de la enconada lucha entre liberales y conservadores sucedió antes con las Leyes de Reforma, decretadas por Juárez en 1859 y 1860, de las cuales derivaría la Ley de nacionalización de los bienes eclesiásticos.

Los lamentables incidentes de latrocinio acaecidos en esas épocas turbulentas, en torno a libros y bibliotecas en vida de Ignacio Ramírez, debieron socavar la política tendente a la institucionalización republicana de los centros bibliotecarios. El robo de fondos bibliográficos por sujetos sin escrúpulos está relacionado con la diáspora de libros al extranjero para su remate. Sin duda, la fuga bibliográfica del siglo $\mathrm{XIX}^{62}$ hacia otros países implicó el aplazamiento y debilitamiento de los proyectos liberales con fines de institucionalizar tan-

${ }_{61}$ Manuel Payno, "La gran biblioteca y la pequeña biblioteca de México", Boletín de la Sociedad de Geografía y Estadística de la República Mexicana, 2a. época, t. 1 (1869): 349. 62 Alicia Perales Ojeda, "Problemas de destrucción y desarraigo en la bibliografía de México", Omnia: Revista de la Coordinación General de Estudios de Posgrado 4, núm. 10 (1988): 61-67; Alicia Perales Ojeda, La cultura bibliográfica en México (México: UNAM, IIB, 2002), 163-167. 
to la conservación del caudal bibliográfico de México como la gestión de los servicios de lectura pública.

Desde una perspectiva general, social y políticamente la Biblioteca Nacional de México está asociada con la restauración del gobierno republicano, por ende, con la victoria del movimiento del liberalismo decimonónico. De tal modo que este centro bibliotecario "desde su fundación se identifica con el triunfo de la república en el siglo XIX".63 Y, dado que a través del movimiento de Reforma se logró someter la Iglesia católica a la autoridad del Estado, fue en el recinto religioso de San Agustín donde se alojó esta biblioteca nacional, transformándose "en un templo laico y republicano con el triunfo de los liberales en 1867".64

El servicio público de biblioteca debía ayudar, junto con otras instituciones culturales, a forjar las virtudes cívicas inherentes al bien público. Ramírez, como uno de los liberales mexicanos más prominentes, tuvo que perfilar un cambio social radical para romper con el legado eclesiástico-colonial, el cual impedía configurar un sistema de escuelas y bibliotecas de orden estatal.

Ante el cierre de esas escuelas y bibliotecas, hasta entonces en manos del clero y al alcance preferentemente de la comunidad religiosa, comenzaron a abrirse las puertas de escuelas y bibliotecas para permitir el acceso al pueblo y afianzar la vida republicana; después de la clausura de las instituciones de enseñanza y lectura, bajo el poder de la Iglesia, se inauguraron las primeras instituciones públicas de educación y lectura pertenecientes al Estado. De la costumbre de leer libros con lecciones banales y dogmáticas, se pasó a fomentar el hábito de leer contenidos liberales; de la impresión de libros eclesiales se convocó a imprimirlos con el fin de propagar con mayor énfasis las ciencias, artes y literatura. Del contorno de la biblioteca clerical se pasó al decisivo perfil de la biblioteca republicana. Y en esta metamorfosis social, política y cultural, el papel intelectual de Ignacio Ramírez fue esencial y sobresaliente.

\footnotetext{
${ }^{63}$ Pablo Mora, "Bienes comunes: objetos y testimonios de la cultura escrita", en Bienes comunes: 150 años de la Biblioteca Nacional de México en 150 objetos, coord. de Cuauhtémoc Padilla Guzmán (México: UNAM, IIB, 2017), 23.

${ }^{64} \mathrm{lbid}$.
} 


\section{Conclusiones}

El potencial ideológico de los impresos y bibliotecas puede ilustrarse con diáfana claridad a través del estudio y análisis de la vida y obra sociopolítica de quienes vivieron con particular intensidad los tiempos del movimiento de Reforma, parte relevante de la historia de México. Entre esos personajes de gran talla histórica resalta Ignacio Ramírez. El pensamiento ilustrado del Nigromante se basó en el conocimiento obtenido en las bibliotecas, en su práctica de la lectura, en el razonamiento y la abstracción sobre una gran variedad de disciplinas, destacando su formación autodidacta y la importancia que dio al impreso como herramienta fundamental de transformación social.

La relevancia de las bibliotecas en su formación fue imprescindible para que comprendiera la necesidad de hacer accesibles las mismas a la gran masa poblacional, interesándose por enriquecer los acervos y mejorar las condiciones de los servicios (horarios, dependientes, cuidados, etc.). Las bibliotecas dejaron de ser vistas como unidades aisladas e independientes, para convertirse en parte de una política pública que poco a poco buscaría su articulación en favor del nuevo proyecto de nación.

En todos los cargos que ejerció en la administración pública, el Nigromante mostró su compromiso de contribuir a la creación y consolidación de las instituciones que sostendrían el nuevo proyecto republicano, muestra de ello fue su particular interés por la educación laica y gratuita y la constitución de servicios públicos que respondieran a las necesidades de todos los mexicanos, sin importar su condición social, económica ni racial.

Como férreo liberal, comprometido con la alfabetización y educación del pueblo mexicano, fue el artífice del desmantelamiento del monopolio bibliotecario y educativo, convirtiendo varios conventos en escuelas y bibliotecas públicas, hechos que contribuyeron al fortalecimiento de libertades como las de enseñanza, prensa y expresión, valores fundamentales de lo que a la postre formaría parte de un programa democrático que supondría una ruptura radical con el orden colonial.

La multiplicación de bibliotecas fue para Ramírez una de las necesidades de la sociedad moderna, una exigencia de la naciente república. Centros bibliotecarios donde los miembros de la sociedad, en su calidad de lectores, pudiesen tener acceso a obras que les permitieran practicar la lectura, escritura y aritmética; bibliotecas que fuesen uno de los bienes comunes para emprender 
una verdadera educación pública; servicios bibliotecarios de carácter público que ayudaran a combatir la ignorancia.

Afirmamos que las bibliotecas en el contexto social y político de Ignacio Ramírez se erigieron como instituciones republicanas; que la Biblioteca Nacional de México ha sido, histórica y culturalmente, la mejor muestra para apreciar el impulso de ciudadanizar el servicio de biblioteca, esto es, de socializar con fines cívicos el servicio de lectura pública bajo la potestad del Estado democráticorepublicano, especialmente a partir de la segunda mitad del siglo XIX.

El movimiento de Reforma, como profunda revolución cultural, transformó radicalmente la estructura bibliotecaria colonial en general y el sistema bibliotecario clerical en particular, definiendo lo que sería el comienzo de las primeras bibliotecas públicas en tiempos de la República Restaurada. Con este triunfo definitivo, la fecha del 30 de noviembre de 1867 ha pasado a la historia de la Biblioteca Nacional de México porque fue entonces cuando, de manera decisiva, se decretó la fundación de este importante repositorio bibliográfico.

La historia de las bibliotecas mexicanas durante el siglo XIX, particularmente la de la Biblioteca Nacional de México, está en deuda con la vida y obra de Ramírez, uno de los personajes centrales del movimiento de Reforma. Su vocación republicana, sostenida con el estudio, la lectura, el pensamiento y la razón, muestra el perfil intelectual de este personaje.

Por último, a más de 200 años de su natalicio, con este escrito deseamos rendir un merecido y respetuoso homenaje a don Ignacio Ramírez.

\section{Referencias}

Alamán, Lucas, José María Andrade et al. Diccionario universal de historia y geografía. Tomo 1. México: Tipografía de Rafael / Librería Andrade, 1853.

Almonte, Juan Nepomuceno. Guía de forasteros, y repertorio de conocimientos útiles. México: Imprenta de I. Cumplido, 1852.

Altamirano, Ignacio Manuel. "Biografía de Ignacio Ramírez". En Obras de Ignacio Ramírez. Tomo 1, i-ixxii. México: Oficina Tip. de la Secretaría de Fomento, 1889.

Altamirano, Ignacio Manuel. "Bosquejos". El Federalista. Periódico Político y Literario, tomo 1, 30 de enero, 13 de febrero de 1871.

Altamirano, Ignacio Manuel. "Crónica de la Semana". El Renacimiento. Periódico Literario 1, 1 de enero de 1889. 
Altamirano, Ignacio Manuel. La literatura nacional: revistas, ensayos, biografías y prólogos. Tomo 1. México: Editorial Porrúa, 2002.

Álvarez Arellano, Lilian. "El Colegio de San Gregorio: modelo de educación para los indios mexicanos". Chicomoztoc 8 (2013): 101-117. Acceso el 12 de agosto de 2020. http://www.descolonizacion.unam.mx/pdf/Ch8_9_gre gorio.pdf.

Aranda Pamplona, Hugo. Biobibliografía de los escritores del Estado de México. México: Universidad Nacional Autónoma de México, Instituto de Investigaciones Bibliográficas, 1978.

Arellano, Emilio. Ignacio Ramírez: El Nigromante: Memorias prohibidas. México: Universidad Autónoma del Estado de México / Editorial Planeta Mexicana, 2016.

Arellano, Emilio. La nueva República: Ignacio Ramírez El Nigromante. México: Editorial Planeta Mexicana, 2012.

Badía Muñoz, Graciela Isabel. "Breve reseña histórica del Instituto Literario de la Ciudad de Toluca hasta la conformación de la Universidad Autónoma del Estado de México". La Colmena: Revista de la Universidad Autónoma del Estado de México, núm. 50 (2006): 22-32.

Barros, Cristina y Catalina Sierra. Ignacio Manuel Altamirano. Iconografía. México: Consejo Nacional para la Cultura y las Artes / Fondo de Cultura Económica / Gobierno Constitucional del Estado de Guerrero, 1993.

Brito Ocampo, Sofía. La Biblioteca Nacional de México: 1822-1929. México: Universidad Nacional Autónoma de México, Instituto de Investigaciones Bibliográficas, 2017.

Campos, Marco Antonio. "La Academia de Letrán". Literatura Mexicana 8, núm. 2 (1997): 569-596.

Carrasco Puente, Rafael. Historia de la Biblioteca Nacional de México. México: Secretaría de Relaciones Exteriores, Departamento de Información para el Extranjero, 1948.

Carreño, Alberto María. La Real y Pontificia Universidad de México 1536-1865. México: Universidad Nacional Autónoma de México, 1961.

Cortés, Amado Manuel. "La transformación de una biblioteca colonial a una biblioteca liberal". En Del manuscrito a la imprenta, el nacimiento de la librería moderna en la Nueva España: la Biblioteca Palafoxiana, 211-218. México; Puebla: Ediciones Eón / Benemérita Universidad Autónoma de Puebla, 2012. 
"Creación de una biblioteca nacional". El Universal, Periódico Político y Literario, 4 de agosto de 1854.

Dublán, Manuel y José María Lozano, comps. "Ley de nacionalización de los bienes eclesiásticos". En Legislación mexicana, ó colección completa de las disposiciones legislativas expedidas desde la independencia de la República. Edición oficial, tomo VIII, 680-683. México: Imprenta del Comercio, de Eduardo Dublán y Chávez, a cargo de M. Lara hijo, 1877.

Fernández Ruiz, Jorge. Juárez y sus contemporáneos. México: Universidad Nacional Autónoma de México, 1986.

Flores Rodríguez, María Eugenia Xilonetl. "Juan de Dios Rodríguez Puebla: en defensa de la instrucción para los indios". En El Estado laico y los derechos humanos: 1810-2010. Tomo 1. Coordinación de Margarita Moreno Bonett y Rosa María Álvarez de Lara, 409-420. México: Universidad Nacional Autónoma de México, Instituto de Investigaciones Jurídicas, Facultad de Filosofía y Letras, 2012.

García Cantú, Gastón. "El Nigromante". En La República de las Letras: asomos a la cultura escrita del México decimonónico. Volumen III: Galería de escritores. Edición de Belem Clark de Lara y Elisa Speckman Guerra. AI Siglo XIX. Ida y Regreso, 205-229. México: Universidad Nacional Autónoma de México, Instituto de Investigaciones Filológicas, Centro de Estudios Literarios, 2005. Gómez Álvarez, Cristina y Guillermo Tovar de Teresa. Censura y revolución: Iibros prohibidos por la Inquisición de México (1790-1819). Madrid; México: Trama Editorial / Consejo de la Crónica de la Ciudad de México, 2009.

Gonzalbo Aizpuru, Pilar. "La lectura de evangelización en la Nueva España". En Historia de la lectura en México: Seminario de Historia de la Educación en México. Coordinación de Josefina Zoraida Vázquez, 9-48. México: Ediciones del Ermitaño / El Colegio de México, 1988.

González Obregón, Luis. La Biblioteca Nacional de México, 1833-1910. Reseña histórica. México: [s. e.], 1910.

Ibarra García, Laura. "Las ideas de Ignacio Ramírez, El Nigromante: su significado en la historia del pensamiento mexicano". Iztapalapa. Revista de Ciencias Sociales y Humanidades 72, núm. 33 (2012): 153-178.

Iguíniz, Juan Bautista. "La Biblioteca Nacional de México". Revista de Historia de América 8 (1940): 57-86.

Iguíniz, Juan Bautista. "El éxodo de documentos y libros mexicanos al extranjero". Boletín de la Biblioteca Nacional, segunda época, tomo 4, núm. 3 (1953): 3-27. 
Jiménez Rueda, Julio. Historia de la literatura mexicana. 6a. ed. México: Ediciones Botas, 1957.

Lafuente, Ramiro. Un mundo poco visible: imprenta y bibliotecas en México durante el siglo XIX. México: Universidad Nacional Autónoma de México, 1992.

Maciel, David. Ignacio Ramírez: ideólogo del liberalismo social en México. México: Secretaría de Cultura / Instituto Nacional de Estudios Históricos de las Revoluciones de México, 2018.

Meneses Morales, Ernesto, Liliana Bedoy Lazo et al. Tendencias educativas oficiales en México 1821-1911: la problemática de la educación mexicana en el siglo XIX y principios del siglo XX. 2a. ed. México: Universidad Iberoamericana, Centro de Estudios Educativos, 1998.

Mora, Pablo. "Bienes comunes: objetos y testimonios de la cultura escrita". En Bienes comunes: 150 años de la Biblioteca Nacional de México en 150 objetos. Coordinación de Cuauhtémoc Padilla Guzmán, 21-29. México: Universidad Nacional Autónoma de México, Instituto de Investigaciones Bibliográficas, 2017.

"Noticias nacionales. Bibliotecas". El Siglo Diez y Nueve, 6a. época, año XXI, tomo 1, núm. 27, 10 de febrero de 1861.

Osorio Romero, Ignacio. Historia de las bibliotecas novohispanas. México: Secretaría de Educación Pública, 1986.

Osorio Romero, Ignacio y Boris Berenzon Gorn. "Biblioteca Nacional de México". En Historia de las bibliotecas nacionales de Iberoamérica. Coordinación de José G. Moreno de Alba y Elsa Margarita Ramírez Leyva, 325-363. México: Universidad Nacional Autónoma de México, Coordinación de Humanidades, 1995.

Payno, Manuel. "La gran biblioteca y la pequeña biblioteca de México". Boletín de la Sociedad de Geografía y Estadística de la República Mexicana, 2a. época, tomo 1 (1869): 349-360.

Perales de Mercado, Alicia. "La Biblioteca Nacional de México, una institución de la Reforma". Omnia: Revista de la Coordinación de Estudios de Posgrado 6, núm. 20 (1990): 89-95.

Perales Ojeda, Alicia. Asociaciones literarias mexicanas: siglo XIX. México: Universidad Nacional Autónoma de México, Centro de Estudios Literarios, 1957.

Perales Ojeda, Alicia. La cultura bibliográfica en México. México: Universidad Nacional Autónoma de México, Instituto de Investigaciones Bibliográficas, 2002. 
Perales Ojeda, Alicia. "Problemas de destrucción y desarraigo en la bibliografía de México". Omnia: Revista de la Coordinación General de Estudios de Posgrado 4, núm. 10 (1988): 57-70.

Prieto, Guillermo. Memorias de mis tiempos. 3a. ed. México: Editorial Porrúa, 2004.

Ramírez, Ignacio. Lecciones de literatura. México: Imprenta de Francisco Díaz de León, 1884.

Ramírez, Ignacio. Libro rudimental y progresivo para la enseñanza primaria. Introducción de Francisco Sosa. México: Oficina Tip. de la Secretaría de Fomento, 1884.

Ramírez, Ignacio. Obras completas. Ignacio Ramírez. El Nigromante. Compilación de David R. Maciel y Boris Rosen Jélomer. 8 vols. México: Centro de Investigación Científica Jorge L. Tamayo, 1984-1989.

Ramírez, Ignacio. Obras de Ignacio Ramírez. 2 tomos. México: Oficina Tip. de la Secretaría de Fomento, 1889.

Rivera Cambas, Manuel. "Biblioteca Nacional". En México pintoresco, artístico y monumental. Tomo 2, 219-221. México: Imprenta de la Reforma, 1882.

Ruiz Castañeda, María del Carmen, Luis Mario Schneider y Miguel Ángel Castro, comps. y eds. La Biblioteca Nacional de México: testimonios y documentos para su historia. México: Universidad Nacional Autónoma de México, Instituto de Investigaciones Bibliográficas, Biblioteca Nacional, 2004.

Sierra Partida, Alfonso. Ignacio Ramírez: espada y pluma. México: Memphis, 1960.

Sosa, Francisco. Biografías de mexicanos distinguidos. México: Oficina Tip. de la Secretaría de Fomento, 1884.

Sosa, Francisco. Introducción a Libro rudimental y progresivo para la enseñanza primaria, de Ignacio Ramírez, i-iv. México: Oficina Tip. de la Secretaría de Fomento, 1884.

Taibo, Paco Ignacio II. La gloria y el ensueño que forjó una patria: de la Revolución de Ayutla a la Guerra de Reforma. México: Planeta, 2017.

Tanck de Estrada, Dorothy. "La enseñanza de la lectura y la escritura en la Nueva España, 1700-1821". En Historia de la lectura en México: Seminario de Historia de la Educación en México. Coordinación de Josefina Zoraida Vázquez, 49-93. México: Ediciones del Ermitaño / El Colegio de México, 1988.

Torre Villar, Ernesto de la. Prólogo a La biblioteca de un reformador, de José Herrera Peña, 15-24. Morelia: Universidad Michoacana de San Nicolás de Hidalgo, 2005. 
Vázquez Mantecón, Carmen, Carlos Herrero Bervera y Alfonso Flamenco Ramírez. Las bibliotecas mexicanas del siglo XIX. México: Secretaría de Educación Pública, Dirección General de Bibliotecas, 1987.

Vigil, José María. "Informe del director". En Inauguración de la Biblioteca Nacional de México, abril 2 de 1884, 1-18. México: Imprenta de Ireneo Paz, 1884.

Zarco, Francisco. Escritos sobre la libertad de imprenta. México: Consejo Nacional para la Cultura y las Artes, 2013. $\mathrm{bg}$ 